\title{
PENGARUH PROFESIONALISME AUDIT, INTENSITAS MORAL UNTUK MELAKUKAN TINDAKAN WHISTLEBLOWING (STUDI PADA KAP DI INDONESIA)
}

\author{
Oleh : \\ Yulita Zanaria \\ Email: \\ Fakultas Ekonomi, Universitas Muhammadiyah Metro
}

\begin{abstract}
Purpose - The purpose of this paper is to to investigate the influence of professionalism auditor and intensity of moral to effect on whistleblowing action of KAP in Indonesia

Design/methodology/approach- The research method used is the population of all auditors who worked on $25 \mathrm{KAP}$ in Indonesia. Sampling technique using nonprobabilitas or not random with convienience sampling method.Tool using regression analysis using $\mathrm{F}$ test and t test with SPSS ver.17.00. The paper ends with a set of hypotheses requiring further research.
\end{abstract}

Findings - The paper finds that the professionalism auditor, intensity of moral simultaneously affect on whistleblowing action of KAP in Indonesia. professionalism auditor variable partially significant affect on whistleblowing action of KAP in Indonesia. Variable intensity of moral has an effect on whistleblowing action of KAP in Indonesia

Originality/value -This paper provides influence of professionalism auditor, intensity of moral, to effect on whistleblowing action of KAP in Indonesia

Keywords: Professionalism auditor, intensity of moral, effect on whistleblowing action

Paper type General review

\section{LATAR BELAKANG}

Seorang auditor dalam melaksanakan audit atas laporan keuangan tidak semata-mata bekerja untuk kepentingan kliennya, melainkan juga untuk kepentingan pihak lain yang mempunyai kepentingan atas laporan keuangan auditan. Untuk dapat mempertahankan kepercayaan dari klien dan dari para pemakai laporan keuangan lainnya, auditor dituntut untuk memiliki kompetensi yang memadai. Oleh karena itu, auditor harus meningkatkan kinerjanya agar dapat menghasilkan produk audit yang dapat diandalkan bagi pihak yang membutuhkan. Guna peningkatan kinerja, hendaknya auditor memiliki sikap profesional dalam melaksanakan audit atas laporan keuangan. 
Gambaran tentang Profesionalisme seorang auditor menurut Hall (1968) dalam Herawati dan Susanto, (2009) tercermin dalam lima hal yaitu: pengabdian pada profesi, kewajiban sosial, kemandirian, kepercayaan terhadap peraturan profesi dan hubungan dengan rekan seprofesi. Dengan profesionalisme yang tinggi, kebebasan auditor akan terjamin. Selain dituntut memiliki tingkat profesionalisme, seorang auditor juga harus mampu menganalisa situasi mencakup karakteristik-karakteristik yang merupakan perluasan dari isu-isu yang terkait dengan isu moral utama dalam sebuah situasi yang akan mempengaruhi persepsi mereka dalam menentukan keputusan, hal ini biasa dikenal dengan intensitas moral. Profesionalisme audit dan intensitas moral merupakan dua aspek yang penting dalam pekerjaan seorang auditor, tidak hanya dalam mengungkapkan kewajaran suatu laporan keuangan tetapi juga dalam mengungkap kecurangan dalam laporan keuangan. Salah satu cara mengungkapkan pelanggaran akuntansi sehingga dapat mengembalikan kepercayaan masyarakat adalah dengan melakukan whistleblowing. Whistleblowing adalah pelaporan yang dilakukan oleh anggota organisasi (aktif maupun non-aktif) mengenai pelanggaran, tindakan ilegal atau tidak bermoral kepada pihak di dalam maupun di luar organisasi.

Whitsleblowing merupakan sebuah proses kompleks yang melibatkan faktor-faktor pribadi dan organisasi. Di Indonesia, beberapa penelitian mengenai intensi melakukan whistleblowing dilakukan di kalangan mahasiswa akuntansi juga telah dilakukan. beberapa diantaranya dilakukan oleh Ghani (2010) dan Sugiyanto, dkk (2011) yang melakukan penelitian mengenai whistleblowing dengan menggunakan aspek persepsi whistleblowing dan intensi melakukan whistleblowing. Ghani (2010) melakukan penelitian mengenai whistleblowing antara mahasiswa akuntansi S1. Pentingnya penelitian ini dilakukan untuk memberikan bukti faktor-faktor yang mempengaruhi antara intensi dalam melakukan Whistleblowing berdasarkan theory of planned behavior (TPB). Penelitian ini dilakukan pada auditor yang bekerja di Kantor Akuntan Publik yang ada di Indonersia yang telah terdaftar di IAIP. Alasan pemilihan auditor sebagai objek penelitian adalah karena auditor merupakan salah satu profesi dalam bidang akuntansi yang paling besar kemungkinannya berhadapan langsung dengan dilema etis ketika melaksanakan tanggung jawab dalam pekerjaannya.

\section{RUMUSAN MASALAH}

Berdasarkan uraian di atas, maka pokok permasalahan dalam penelitian ini akan dirumuskan dalam bentuk pertanyaan yaitu sebagai berikut:

1. Apakah auditor yang mempunyai profesionalisme yang tinggi akan mempengaruhi untuk melakukan whistleblowing?

2. Apakah auditor yang mempunyai intensitas moral yang tinggi akan mempengaruhi untuk melakukan whistleblowing? 


\section{KAJIAN TEORITIS}

\section{Teori Perilaku Terencana (Theory Of Planned Behaviour)}

Teori Perilaku Terencana (Theory of Planned Behavior) merupakan perluasan dari Theory of Reasoned Action (TRA) yang dikembangkan oleh Icek Ajsen dan Martin Fishbein (1980). Ajzen dan Fishbein mengembangkan teori TPB dengan menambah konstruk yang belum ada di TRA yaitu persepsi konrol perilaku (perceived behavioral control). TPB bertujuan untuk memprediksi dan memahami dampak niat berperilaku, mengidentifikasi strategi untuk merubah perilaku serta menjelaskan perilaku nyata manusia. Dalam hubungan ini TPB diasumsikan bahwa manusia yang bersifat rasional akan menggunakan informasi yang ada secara sistematik kemudian memahami dampak perilakunya sebelum memutuskan untuk mewujudkan perilaku tersebut.

\section{PROFESIONALISME AUDIT}

\section{a. Pengertian Profesionalisme}

Menurut pengertian umum, seseorang dikatakan profesional jika memenuhi tiga kriteria, yaitu mempunyai keahlian untuk melaksanakan tugas sesuai dengan bidangnya, melaksanakan suatu tugas atau profesi dengan menetapkan standard baku di bidang profesi yang bersangkutan dan menjalankan tugas profesinya dengan mematuhi Etika Profesi yang telah ditetapkan. Profesi dan profesionalisme dapat dibedakan secara konseptual. Profesi merupakan jenis pekerjaan yang memenuhi beberapa kriteria, sedangkan profesionalisme adalah suatu atribut individul yang penting tanpa melihat suatu pekerjaan merupakan suatu profesi atau tidak (Lekatompessy, 2003 dalam Herawati dan Susanto, 2009:3). Secara sederhana, profesionalisme berarti bahwa auditor wajib melaksanakan tugas-tugasnya dengan kesungguhan dan kecermatan.

Sebagai seorang yang professional, auditor harus menghindari kelalaian dan ketidakjujuran. Maali, B (2010) menyebutkan bahwa profesionalisme merupakan bentuk tanggung jawab individu agar berperilaku lebih baik dari sekedar mematuhi undang-undang dan peraturan masyarakat yang ada.

\section{B. CARA AUDITOR MEWUJUDKAN PERILAKU PROFESIONAL}

Vinnicombe, T. (2010) dalam Merdikawati (2012) menyebutkan bahwa citra akuntan memburuk seiring terungkapnya kasus-kasus manipulasi akuntansi di perusahaanperusahaan besar ternama di dunia. Hal ini merupakan sinyal buruk di dunia akuntansi karena kepercayaan masyarakat kepada para akuntan mulai menurun. Profesionalisme yang dianggap sebagai salah satu karakteristik yang kuat bagi para akuntan namun kini rusak karena adanya kasus manipulasi akuntansi. Merdikawati menyebutkan bahwa profesionalisme sangat penting untuk melakukan whistleblowing

Menurut Mulyadi (2002) dalam Noveria (2006) menyebutkan bahwa pencapaian kompetensi profesional akan memerlukan standar pendidikan umum yang tinggi diikuti oleh pendidikan khusus, pelatihan dan uji profesional dalam subyek-subyek (tugas) yang relevan dan juga adanya pengalaman kerja. Oleh 
karena itu untuk mewujudkan Profesionalisme auditor, dilakukan beberapa cara antara lain pengendalian mutu auditor, review oleh rekan sejawat, pendidikan profesi berkelanjutan, meningkatkan ketaatan terhadap hukum yang berlaku dan taat terhadap kode perilaku profesional.

IAI berwenang menetapkan standar (yang merupakan pedoman) dan aturan yang harus dipatuhi oleh seluruh anggota termasuk setiap kantor akuntan publik lain yang beroperasi sebagai auditor independen. Persyaratan-persyaratan ini dirumuskan oleh komite komite yang dibentuk oleh IAI. Ada tiga bidang utama di mana IAI berwenang menetapkan standar dan memuat aturan yang bisa meningkatkan perilaku prefesional seorang auditor, yaitu standar auditing, standar kompilasi dan penelaahan laporan keuangan, Standar atestasi lainnya.

\section{INTENSITAS MORAL}

Intensitas moral dapat dikaitkan dengan konsep persepsi kontrol perilaku dalam teori perilaku terencana (theory of planned behavior). Persepsi kontrol perilaku merupakan keyakinan seseorang bahwa persepsi yang dimilikinya merupakan hasil dari kontrol dirinya sendiri mengenai persepsiperilaku tersebut (Astrie, 2015). Pendapat lainnya dikemukakan oleh Kreshasturi (2014) bahwa intensitas moral adalah sebuah konstruk yang mencakup karakteristikkarakteristik yang merupakan perluasan dari isu-isu yang terkait dengan isu moral utama dalam sebuah situasi yang akan mempengaruhi persepsi individu mengenai masalah etika dan intensi keperilakuan yang dimilikinya.

Jones (1991) dalam Novius (2011) mengidentifikasi bahwa intensitas moral yang mempengaruhi proses pengambilan keputusan seseorang dan tingkat intensitas moral yang bervariasi. Intensitas moral bersifat multidimensi dan komponen-komponen bagiannya merupakan karakteristik dari isu-isu moral. Jones (1991) mengidentifikasi bahwa ada enam elemen intensitas moral yang mempengaruhi proses pengambilan keputusan meliputi: Konsensus sosial (social consensus), besaran konsekuensi (the magnitude of consequences), probabilitas efek (probability of effect), kesegeraan temporal (temporal immediacy), kedekatan (proximity), dan konsentrasi efek (concentration of effect).

\section{WHISTLEBLOWING}

Komite Nasional Kebijakan Governance (2008) mendefinisikan whistleblowing sebagai pengungkapan tindakan pelanggaran atau pengungkapan perbuatan yang melawan hukum, perbuatan tidak etis atau tidak bermoral atau perbuatan lain yang dapat merugikan organisasi maupun pemangku kepentingan, yang dilakukan oleh karyawan atau pimpinan organisasi kepada pimpinan organisasi atau lembaga lain yang dapat mengambil tindakan atas pelanggaran tersebut. Pengungkapan ini umumnya dilakukan secara rahasia (confidential). Sedangkan Sonny

Keraf (2008) mendefinisikan whistleblowing sebagai tindakan yang dilakukan oleh seorang atau beberapa orang karyawan untuk membocorkan kecurangan entah yang dilakukan oleh perusahaan atau atasannya kepada pihak lain.

Near dan Miceli (1985) dalam Vinnicombe, T. (2010) mendefinisikan whistleblowing sebagai pengungkapan oleh anggota organisasi (mantan atau yang 
masih menjadi anggota) atas suatu praktik-praktik ilegal, tidak bermoral, atau tanpa legitimasi dibawah kendali pimpinan kepada individu atau organisasi yang dapat menimbulkan efek tindakan perbaikan. Dengan demikian praktik atau tindakan kecurangan dapat dilakukan oleh karyawan atau oleh manajemen perusahaan. Sedangkan pelapor kecurangan, umumnya lebih sering dilakukan oleh bawahan/karyawan atau lebih dikenal dengan istilah whistleblower. Sulistomo (2012) menyebutkan bahwa menurut PP No.71 Tahun 2000, whistleblower adalah orang yang memberi suatu informasi kepada penegak hukum atau komisi mengenai terjadinya suatu tindak pidana korupsi.

Definisi antara whistleblower berbeda dengan pelapor. Seorang individu disebut pelapor jika ia melihat adanya tindakan yang tidak etis dalam kehidupan sehari-hari. Sedangkan whistleblower adalah seorang individu yang melaporkan terjadinya kecurangan dalam proses pelaksanaan penugasan kerja dalam organisasi baik yang dilakukan oleh rekan kerjanya maupun atasannya dan tentunya melanggar aturan atau norma yang berlaku. Elias (2008) menyatakan bahwa Whistleblowing dapat terjadi dari dalam (internal) maupun luar (eksternal). Internal whistleblowing terjadi ketika seorang karyawan mengetahui kecurangan yang dilakukan karyawan lainnya kemudian melaporkan kecurangan tersebut kepada atasannya. Sedangkan external whistleblowing terjadi ketika seorang karyawan mengetahui kecurangan yang dilakukan perusahaan lalu memberitahukannya kepada masyarakat karena kecurangan itu akan merugikan masyarakat

Menurut Komite Nasional Kebijakan Governance (KNKG) dalam Sagara (2013) bahwa

dalam Pedoman Sistem Pelaporan Pelanggaran adalah pengungkapan tindakan pelanggaran atau perbuatan yang melawan hukum, tidak etis/tidak bermoral atau perbuatan lain yang dapat merugikan organisasi atau pemangku kepentingan, yang dilakukan oleh karyawan atau pimpinan organisasi kepada pimpinan organisasi atau lembaga lain yang dapat mengambil tindakan atas pelanggaran tersebut. Menurut Vinten dalam Rahardian (2010) disebutkan bahwa seorang pelapor pelanggaran/kecurangan (whistleblower) di negara barat rata-rata dijadikan panutan/role model.

\section{METODE PENELITIAN}

Berdasarkan latar belakang penelitian yang telah dijelaskan pada bab sebelumnya, penelitian ini menggunakan jenis penelitian kualitatif deskriptif. Pada penelitian deskriptif, data yang dianalisis tidak untuk menerima atau menolak hipotesis melainkan hasil analisis itu berupa deskripsi dari gejala-gejala yang diamati. Pemilihan ini didasarkan pada pendapat Kasiram (2010) yang menyatakan bahwa penelitian kualitatif adalah suatu konsep keseluruhan untuk mengungkap rahasia tertentu, dilakukan dengan menghimpun data dalam keadaan sewajarnya, mempergunakan cara bekerja yang sistematik, terarah, dan dapat dipertanggungjawabkan, sehingga tidak kehilangan sifat ilmiahnya atau serangkaian kegiatan atau proses menjaring data/informasi yang bersifat sewajarnya, mengenai suatu masalah dalam kondisi aspek atau bidang kehidupan tertentu pada obyeknya. 
Selain itu, Moleong (2012) juga menyatakan bawa penelitian kualitatif adalah penelitian yang bermaksud untuk memahami fenomena tentang apa yang dialami oleh subjek penelitian misalnya perilaku, persepsi, motivasi, tindakan, dll., secara holistik, dan dengan cara deskripsi dalam bentuk kata-kata dan bahasa, pada suatu konteks khusus yang alamiah dan dengan memanfaatkan beerbagai metode alamiah

\section{SUMBER DATA}

Sumber data dibagi menjadi dua, yaitu sumber data primer dan sumber data sekunder. Sumber primer merupakan sumber data yang langsung memberikan data kepada pengumpul data, sedangkan sumber sekunder merupakan sumber yang data yang tidak langsung memberikan data kepada pengumpul data, namun diperoleh melalui media perantara (Sugiyono, 2011). Dalam penelitian ini, data primer diperoleh melalui wawancara dan kuesioner dengan berbagai pihak yang terkait dengan penelitian dan juga observasi yaitu ketika pelaksanaan audit internal sednag berlangsung.

Sedangkan data sekunder yang diperoleh peneliti dalam penelitian ini adalah dokumen-dokumen yang berkaitan dengan penelitian, baik yang diperoleh langsung dari organisasi terkait maupun yang telah dipublikasikan di jaringan internet. Dalam penelitian ini teknik pengambilan sampel menggunakan metode nonprobabilitas atau secara tidak acak, elemen-elemen populasi tidak mempunyai kesempatan yang sama untuk terpilih menjadi sampel. Pemilihan sampel berdasarkan kemudahan (convenience sampling), metode ini memilih sampel dari elemen populasi (orang atau kejadian) yang datanya mudah diperoleh peneliti (Indriantoro dan Supomo, 2002). Dalam penelitian lapangan penulis melakukan peninjauan secara langsung ke objek penelitian untuk memperoleh data primer. Penjelasan dari pengumpulan datanya adala sebagai berikut:

\section{Wawancara}

Teknik wawancara dapat dilakukan dengan mengadakan wawancara dengan berbagai orang secara individu, ataupun sekelompok orang yang akan dijadikan narasumber. Wawancara dilakukan dengan tanya jawab secara langsung melalui guiding questions dengan pihak yang berwenang yaitu seluruh auditor yang bekerja pada KAP di Indonesia.

\section{Observasi}

Observasi adalah metode pengumpulan data, dengan cara melakukan pengamatan terhadap objek penelitian. Penggunaan teknik observasi mengharuskan peneliti melakukan pengamatan secara langsung terhadap objek penelitian, tanpa berusaha melakukan intervensi terhadap keadaan dan kejadian yang sedang berlaku pada objek.

\section{Dokumentasi}

Dokumentasi adalah salah satu metode pengumpulan data dengan cara melakukan analisis terhadap semua catatan dan dokumen yang dimiliki oleh 
organisasi yang terpilih sebagai objek penelitian, atau data dari individu sebagai objek penelitian.

\section{OBJEK PENELITIAN}

Objek dalam penelitian ini adalah auditor yang bekerja di Kantor Akuntan Publik yang ada di Indonesia yang telah terdaftar di IAIP. Alasan pemilihan auditor sebagai objek penelitian adalah karena auditor merupakan salah satu profesi dalam bidang akuntansi yang paling besar kemungkinannya berhadapan langsung dengan dilema etis ketika melaksanakan tanggung jawab dalam pekerjaannya. Setelah dilakukan tehnik acak maka didapat sampel penelitian yang mewakili Kantor Akuntan Publik (KAP) yang ada di Indonesia yang telah terdaftar di IAIP yaitu sebanyak 25 KAP.

\section{TEKNIK ANALISIS DATA}

Analisis data dilakukan dengan cara mencari dan menyusun secara sistematis data yang diperoleh dari lapangan dengan mengorganisasikannya ke dalam kategori, menjabarkan ke dalam unit-unit, melakukan sintesa, menyusun ke dalam pola, memilih hal-hal yang penting dan akan dipelajari, dan membuat kesimpulan yang mudah dipahami baik bagi diri sendiri maupun orang lain (Sugiyono, 2011). Langkah-langkah analisis data yang dilakukan dalam penelitian ini adalah sebagai berikut:

1. Mengumpulkan data-data yang diperlukan dan berkaitan dengan obyek penelitian. Metode pengumpulan data dilakukan seperti yang telah disebutkan sebelumnya.

2. Data-data yang diperoleh kemudian dipelajari dan disusun sedemikian rupa, sehingga dapat dipergunakan sebagai dasar dalam pembahasan dan pemecahan masalah.

3. Menganalisis semua data yang telah diperoleh dan membandingkan data dengan teori- teori tentang fungsi dan efektivitas audit internal khususnya pada organisasi.

4. Menelaah lebih lanjut bagaimana tingkat profesionalisme auditor dan intensitas moral yang mereka miliki dalam menghadapi tugas mereka serta dampaknya dalam melakukan tindakan whistleblowing.

5. Dari data yang telah tersaji kemudian ditarik kesimpulan yang masih bersifat sementara. Jika terdapat data yang kurang valid maka dilakukan verifikasi ke lapangan hingga mendapatkan bukti yang valid sehingga kesimpulan bersifat kredibel.

6. Membuat kesimpulan dan saran.

\section{ANALISIS HASIL PENELITIAN}

Setelah melakukan wawancara dengan berbagai pihak yang terkait dengan penelitian serta observasi langsung dengan sampel yang diteliti dan memperoleh dokumen-dokumen yang berkaitan dengan penelitian, baik yang diperoleh langsung dari organisasi terkait maupun yang telah dipublikasikan di jaringan internet, selanjutnya penulis menganalisis semua data yang telah diperoleh dan membandingkan data dengan teori- teori yang ada. Langkah selanjutnya 
kemudian menelaah lebih lanjut bagaimana pengaruh profesionalisme audit dan intensitas moral terhadap tindakan untuk melakukan whistleblowing.

\section{a. Profesionalisme auditor terhadap tindakan untuk melakukan whistleblowing}

Di dalam teori Perilaku Terencana (Theory Of Planned Behaviour) yang sudah dipaparkan di atas dijelaskan bahwa tugas akan dilaksanakan karena tugas tersebut akan memberikan manfaat atau keuntungan bagi seseorang. Selain hal tersebut, tugas juga dilaksanakan karena memang tugas tersebut merupakan tugasnya. Hal tersebut mencerminkan bahwa terdapat indikasi adanya dedikasi seseorang terhadap pekerjaannya, baik pekerjaan itu menyenangkan maupun tidak. Seorang auditor akan senang dan terdorong melihat dedikasi dan idealisme teman seprofesinya dan antusias, memiliki komitmen terhadap profesinya. Merdikawati (2012) menemukan bahwa profesionalisme sangat penting untuk melakukan whistleblowing. Sagara (2013) membuktikan dalam penelitiannya bahwa semakin tinggi profesionalisme internal auditor (dimensi dedikasi terhadap pekerjaan) maka intensi untuk melakukan whistleblowing menjadi tinggi.

Adanya pengaruh yang signifikan dari dedikasi terhadap pekerjaan tehadap intensitas melakukan whistleblowing dapat dikarenakan adanya posisi yang ditanggung terhadap pekerjaan yang diemban auditor. Sebagai seorang auditor, ada hal yang melekat pada diri auditor dalam memilih mana yang harus diutamakan. Hal ini terkait pula dengan faktor yang dapat mempengaruhi kepuasan kerja auditor yang mengedepankan peran dan dedikasi individu terhadap pekerjaan sebagai auditor. Berdasarkan wawancara dan observasi serta analisa terlihat jelas bahwa para auditor yang memiliki tingkat profesionalisme tinggi memiliki komitemen yang tinggi terhadap profesi / pekerjaan atau tugas yang dipikul mereka, sehingga mereka cenderung berani berintesi dalam melakukan whistleblowing.

Hasil penelitian ini menunjukkan adanya konsistensi yang dilakukan Ghani (2010), membuktikan bahwa Profesionalisme berpengaruh terhadap Tindakan Whistleblowing. Profesional adalah sebuah komponen identitas sosial seseorang yang merupakan gagasan bahwa seseorang mengklasifikasikan diri sendiri berdasarkan profesinya. Penelitian Herawaty dan Susanto (2008) dalam (2014) meneliti tentang Profesionalisme, Pengetahuan Akuntan Publik dalam Mendeteksi Kekeliruan, Etika Profesi dan Pertimbangan Tingkat Materialitas. Hasilnya menunjukkan bahwa Profesionalisme mempunyai koefisien regresi bernilai positif $(0,231)$ dan signifikan. Aranya, Pollack et al (1981) dalam Chiang (2012) mendefinisikan identitas profesional sebagai kekuatan seseorang dengan keterlibatannya dalam sebuah profesi. Identitas profesional merepresentasikan sikap dalam dalam konsep teori perilaku terencana (theory of planned behaviour). Sikap adalah keadaan dalam diri manusia yang dapat menggerakkan manusia untuk bertindak atau tidak bertindak. Salah satu sikap seorang auditor untuk menunjukkan identitas profesional adalah melalui kepatuhan terhadap standar audit dan kode etik profesi auditor yang diatur dalam Standar Profesional Akuntan Publik dan Kode Etik Profesi Akuntan Publik. 


\section{b. Intensitas moral terhadap tindakan untuk melakukan whistleblowing}

Jones (1991) dalam Novius (2011) mengidentifikasi bahwa intensitas moral yang mempengaruhi proses pengambilan keputusan seseorang dan tingkat intensitas moral yang bervariasi. Penelitian yang dilakukan Novius (2011) telah menguji pengaruh komponen intensitas moral dalam proses pembuatan keputusan moral. Hasilnya, komponen intensitas moral memiliki pengaruh secara signifikan terhadap proses pembuatan keputusan moral. Alvian (2010) menguji pengaruh dilema intensitas moral dan penilaian etis terhadap niat berperilaku etis. Hasilnya menunjukkan variabel dilema intensitas moral berpengaruh signifikan terhadap niat berperilaku etis. Dewi (2008) menguji komponen intensitas moral yaitu konsensus sosial, besaran konsekuensi, dan kedekatan terhadap intensi untuk berperilaku.

Hasil dari proses analisa diketahui bahwa intensitas moral berpengaruh terhadap tindakan auditor untuk melakukan whistleblowing. Fenomena pada lingkungan kerja auditor memperlihatkan terdapat faktor-faktor intensitas moral yang bersifat multidimensi dan komponen-komponen bagiannya merupakan karakteristik dari isu-isu moral yang mampu mempengaruhi persepsi dan tindakan seorang auditor untuk untuk melakukan whistleblowing. Adapun faktor-faktor intensitas moral tersebut sesuai dengan acuan Jones (1991) yang mengidentifikasi bahwa ada enam elemen intensitas moral yang mempengaruhi proses pengambilan keputusan yaitu:

1. Besaran konsekuensi (Magnitude of Consequences), didefinisikan sebagai jumlah kerugian (atau manfaat) yang dihasilkan oleh pengorbanan (atau pemanfaatan) dari sebuah tindakan moral. Berdasarkan wawancara dan observasi serta data lainnya didapat bahwa seorang auditor selalu mempertimbangkan hasil dari konsekwensi yang akan mereka terima akibat tindakan moral terkait dengan tugas yang mereka lakukan.

2. Konsensus Sosial (Social Consensus), didefinisikan sebagai tingkat kesepakatan sosial bahwa sebuah tindakan dianggap salah atau benar. Seorang auditor selalu berdiskusi dengan rekan kerjanya sebelum mengambil sebuah tindakan.

3. Probabilitas Efek (Probability of Effect) merupakan sebuah fungsi bersama dari kemungkinan bahwa tindakan tertentu akan secara aktual mengambil tempat dan tindakan tersebut akan secara aktual menyebabkan kerugian (manfaat) yang terprediksi. Seorang auditor selalu mempunyai pemikiran ke depan terkait dengan tindakan yang akan mereka lakukan, apakah hal tersebut akan memberikan manfaat atau sebaliknya. Persepsi positif tertanam pada diri seorang auditor apabila mereka berniat melakukan tindakan whistleblowing maka akan memberikan manfaat baik bagi dirinya maupun perusahaan serta lingkungan sekitar.

4. Kesegeraan Temporal (Temporal Immediacy) adalah jarak atau waktu antara pada saat terjadi dan awal mula konsekuensi dari sebuah tindakan moral tertentu (waktu yang makin pendek menunjukkan kesiapan yang lebih besar). Pada diri seorang auditor terdapat intensitas moral dalam menghadapi prediksi-prediksi kemungkinan yang akan terjadi dari gejala yang ada, untuk 
itu mereka pada umumnya telah melakukan persiapan yang cukup sebelum mengambil tindakan melakukan tindakan whistleblowing

5. Konsentrasi Efek (Concentration of Effect) adalah sebuah fungsi infers dari jumlah orang yang mempengaruhi dan dipengaruhi oleh sebuah tindakan yang dilakukan. Auditor yang memiliki perasaan kepentingan yang tertinggi akan bertindak secara amoral yang akan menghasilkan konsentrasi efek tinggi.

6. Kedekatan (Proximity) adalah perasaan kedekatan (sosial, budaya, psikologi atau fisik) yang dimiliki oleh pembawa moral (moral agent) untuk si pelaku dari kejahatan (kemanfaatan) dari suatu tindakan tertentu. Konstruk kedekatan ini secara intuitif dan alasan moral menyebabkan seseorang lebih peduli pada orang-orang yang berada didekatnya (secara sosial, budaya, psikologi ataupun fisik) daripada kepada orang-orang yang jauh darinya. Seorang auditor, sebelum memutuskan untuk mengambil tindakan akan mempertimbangkan apakah keputusannya akan mempengaruhi rekan kerjanya atau tidak.

Hasil penelitian ini mendukung penelitian Lai (2011) yang melakukan penelitian mengenai hubungan antara intensitas moral dengan tindakan melaporkan pelanggaran. Hasilnya menunjukkan bahwa intensitas moral mempengaruhi tindakan untuk melakukan whistleblowing dengan menggunakan komitmen organisasi sebagai variabel pemoderasi. Penelitian Lai mendukung penelitian sebelumnya yang dilakukan oleh Jones (1991) bahwa intensitas moral yang kuat secara signifikan mempengaruhi niat moral. Penelitian ini juga mendukung penelitian Taylor, (2010), Shawver (2011) yang menguji pengaruh intensitas moral pada niat pelaporan. Dalam penelitian tersebut intensitas moral terbukti mempengaruhi niat moral untuk melaporkan tindakan pelanggaran dalam situasi manajemen laba.

\section{KESIMPULAN}

Berdasarkan hasil penelitian yang dilakukan penulis, dapat ditarik kesimpulan sebagai berikut:

1. Adanya pengaruh yang signifikan dari dedikasi terhadap pekerjaan tehadap intensitas melakukan whistleblowing dapat dikarenakan adanya posisi yang ditanggung terhadap pekerjaan yang diemban auditor. Hasil penelitian ini menunjukkan adanya konsistensi yang dilakukan Ghani (2010), Vinnicombe, T. (2010), Merdikawati (2012) yang membuktikan bahwa Profesionalisme berpengaruh terhadap Tindakan Whistleblowing.

2. Hasil dari proses analisa diketahui bahwa intensitas moral berpengaruh terhadap tindakan auditor untuk melakukan whistleblowing. Fenomena pada lingkungan kerja auditor memperlihatkan terdapat faktor-faktor intensitas moral yang bersifat multidimensi dan komponen-komponen bagiannya merupakan karakteristik dari isu-isu moral yang mampu mempengaruhi persepsi dan tindakan seorang auditor untuk untuk melakukan whistleblowing. Hasil penelitian ini mendukung penelitian Lai (2011) yang melakukan penelitian mengenai hubungan antara intensitas moral dengan tindakan melaporkan pelanggaran. Penelitian ini juga mendukung penelitian Taylor (2010), Shawver (2011) yang membuktikan intensitas moral berpengaruh terhadap niat pelaporan. 


\section{DAFTAR PUSTAKA}

AAOIFI. (2010). Accounting and Auditing Organization for Islamic Financial Institutions. Financial Accounting Standard. Manama, Bahrain

Andi Novius \& Arifin, Perbedaan Persepsi Intensitas Moral Mahasiswa Akuntansi dalam Proses Pembuatan Keputusan Moral (Studi Survei pada Mahasiswa Akuntansi S1, Pendidikan Profesi Akuntansi (PPA) Universitas Diponegoro Semarang).

Aranya et al, 1981, Community Size, Socialization, and the Work Needs of Professionals, Academy of Management Journal.

Arikunto S, 2006. Prosedur Penelitian Suatu Pendekatan Praktik, Ed Revisi VI, Jakarta: Penerbit PT Rineka Cipta.

Ashraf, J. and W.I. Ghani, 2005. Accounting development in pakistan. The International Journal of Accounting, 40: 175-201.

Chiang, Hsiang-Tsai and Lin, Shu-Lin. 2012. Effect Of Auditor's Judgment And Specialization On Their Differential Opinion Between Semiannual And Annual Financial Reports. Global Journal of Business Research 6. 4 : 1-22

Destriana Kurnia Kreshastuti, 2014, Analisis Faktor-Faktor Yang Mempengaruhi Intensi Auditor Untuk Melakukan Tindakan Whistleblowing (Studi Pada Kantor Akuntan Publik Semarang), Jurnal, Semarang: Undip.

Elias, 2008, Auditing Student Professional Commitment and Anticipatory Socialization and Their Relationship to Whistleblowing, Managerial Auditing ,Journal, Vol. 23, No. 3, 283-294.

Ghani, Rahardian M. 2010, Analisis Perbedaan Komitmen Profesional dan Sosialisasi Antisipatif Mahasiswa PPA dan Non-PPA pada Hubungannya dengan Whistleblowing, Skripsi Tidak Dipublikasikan, Program Sarjana Universitas Diponegoro.

Hendriadi, Firmansyah, 2012, Pengaruh Intensitas Moral, Kesadaran Risikodan pertimbangan Moral Terhadap Keputusan Pembelian Software Windows 7 Bajakan pada Mahasiswa di Surabaya, Sekolah Tinggi Ilmu Ekonomi Perbanas, Surabaya.

http://www.bappenas.go.id/print/27/semnas-peran-sistem-whistleblowingdalampandangan-ternal-auditor-pemerintah/

Indriantoro, dan Supomo, 2002.Metodologi Penelitian Bisnis untuk Akuntansidan Manajemen, Edisi Pertama, BPFE-Yogyakarta, Yogyakarta. 
International Auditing and Assurance Standards Board. 2010. International Standard on Auditing 2010: Overall Objectives of The Independent Auditor and The Conductof An Audit in Accordance with International Standards on Auditing. International Federation of Accountants

Jeffrey, C. dan N.Weatherholt, 1996, Ethical Development, Professional Commitment, and Rule Observance Attitudes: A Study of CPAs and Corporate Accountants. Behavioral Research in Accounting, Vol.8: 8-31.

Jones, R., Pandlebury, M, 1991, Public Sector Accounting, Prentice Hall, UK.

Keraf, Sonny. 2008. Etika Bisnis, Penerbit Kanisius, Yogyakarta.

Kuruppu, G.C.J., 2010. Development of central government accounting in sri lanka: Three perspectives on the accounting changes. DOI no. 25-2010, HHB

Lai, C.Tsung and C.P. Chen, 2011, Moral Intensity and Organizational Commitment: Effects on Whistleblowing Intention and Behavior,European Business Ethics Network Ireland Research Conference, June 8-10.

Noveria. (2006). Pengaruh Profesionalisme Auditor Internal terhadap Work Outcome Audior Internal. Skripsi. Tidak Dipublikasikan. UNPAD Bandung

Maali, B., \& Napier, C. (2010). Accounting, religion and organizational culture: the creation of Jordan Islamic Bank. Journal of Islamic Accounting and Business Research. 1(2).

Shawver, Tara, 2011, The Effects of Moral Intensity on Whistleblowing Behaviour Accounting Professional, Journal of Forensic and Investigate Accounting, Vol. 3 Iss.2.

Sugiyono, 2006, Metode Penelitian Bisnis. Bandung: CV. Alfabeta.

Taylor, E.Z dan Mary B. Curtis, 2010, An Examination Of The Layers Workplace Influence In Ethical Judgement: Whistleblowing Likelihood and Perseverance in Public Accounting, Journal of Business Ethics, Vol.93, pp. 21-37.

Yusuar Sagara, 2013, Profesionalisme Internal Auditor Dan Intensi Melakukan Whistleblowing, Jurnal, Jakarta: STIE Ahmad Dahlan.

Vinnicombe, T. (2010). AAOIFI reporting standards: Measuring compliance. Advances in Accounting,incorporating Advances in International Accounting, 26(1), 55-65. 